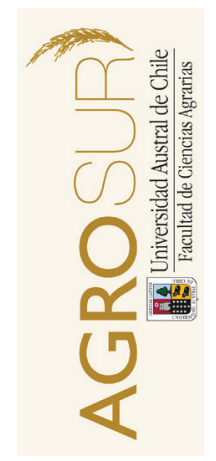

\title{
Vegetación y flora leñosa de la comuna de Tortel (Región de Aisén, Chile): una clave de determinación de especies
}

\author{
Vegetation and woody flora of Tortel commune (Aisén Region, Chile): \\ a key to identify the species
}

\author{
San Martín, C. ${ }^{a^{*}}$, Montenegro, D. ${ }^{b}$, Pérez, Y. ${ }^{a}$, Solís, J.L. ${ }^{a}$ \\ ${ }^{1}$ Instituto de Ciencias Ambientales y Evolutivas, Facultad de Ciencias, \\ Universidad Austral de Chile, Casilla 567, Valdivia, Chile. \\ ${ }^{2}$ Teniente Merino $N^{\circ} 441$, Ingeniero Ejecución Agrícola, Consultora, Cochrane, Aisén, Chile.
}

\begin{tabular}{l} 
A R T I C L E I N F O \\
\hline Article history: \\
Received: 04.08.14 \\
Accepted: 28.09 .14 \\
\hline Keywords: \\
Chilean Patagonia \\
Natural resources \\
Plant communities \\
Woody plants \\
Species determination \\
\hline Original Research Article, \\
Plant Science
\end{tabular}

*Corresponding author:

Cristina San Martín P.

E-mail address:

csanmart@uach.cl

\begin{abstract}
A B S T R A C T
Tortel Commune is located in the South-West end of the Aisen Region with a cold and humid oceanic climate. Its vegetation consists of five forest communities (coigüe of Chiloe forest, coigüe of Magallanes forest, coigüe forest and ñire-colihue forest) only the last are deciduous, a shrubby and other subshrubby (stumpy scrub of lenga and high Andean brecillo steppe) and three peatbogs (Sphagnum bog, pulvinate bog and grass bog) that provide habitats for the studied flora. A brief description of each community were made. The woody flora of Tortel consists of 61 species, of which only three are introduced: Populus nigra, Rosa rubiginosa and Salix fragilis. This flora is dominated by shrubs with 28 species and trees with 15 and three can occur as trees or bushes (Nothofagus antarctica, Nothofagus pumilio and Tepualia stipularis). Also includes two lianas (Campsidium valdivianum and Griselinia ruscifolia) and a small tree fern (Blechnum magellanicum). The shapes of the bushes are diverse and include them one bambus bush (Chusquea culeou), one throotle liane (Raukaua laetevirens) and three passive climbers (Lebetanthus myrsinites, Mitraria coccinea and Philesia magellanica). The richest communities in woody species is the coigüe of Chiloe forest and the poorest stunted lenga bush. Finally a parallel key for determining the woody species of the Commune of Tortel that were shown in this paper is presented.
\end{abstract}

\section{RESUMEN}

La Comuna de Tortel se ubica en el extremo Sur-Occidental de la Región de Aisén que posee un clima oceánico frío muy húmedo. Su vegetación está formada por 5 comunidades boscosas (bosque de coigüe de Chiloé, bosque de coigüe de Magallanes, bosque de coigüe y bosque de ñire-colihue) sólo la última es caducifolia, una arbustiva y otra subarbustiva (matorral achaparrado de lenga y estepa alto andina de brecillo) y tres turbales (esfagnosos, pulvinados y graminosos) que sirven de hábitat a la flora estudiada, por lo cual se hace una breve descripción de cada comunidad. La flora leñosa de Tortel está formada por 61 especies, de las cuales sólo tres son introducidas: Populus nigra, Rosa rubiginosa y Salix fragilis. En esta flora dominan los arbustos con 28 especies y los árboles con 15 además existen tres especies que pueden presentarse como árboles o como arbustos (Nothofagus antarctica, Tepualia stipularis y Nothofagus pumilio). También figuran dos lianas (Campsidium valdivianum y Griselinia ruscifolia) y un pequeño helecho arborescente (Blechnum magellanicum). Las formas de los arbustos son diversas, destacando en ellas un arbusto bambúseo (Chusquea culeou), uno estrangulador (Raukaua laetevirens) y tres semitrepadores (Lebetanthus myrsinites, Mitraria coccinea y Philesia magellanica). La comunidad más rica en especies leñosas resultó ser el bosque de coigüe de Chiloé y la más pobre, el matorral achaparrado de lenga. Por último se entrega una clave paralela que permite determinar las especies leñosas de la Comuna de Tortel que fueran presentadas en este trabajo.

Palabras clave: Patagonia chilena, Recursos naturales, Comunidades vegetales, Plantas leñosas, Determinación de especies.

\section{INTRODUCCIÓN}

Caleta Tortel es un poblado único en Chile ubicado en el extremo sur-occidental de la Región de Aisén, pues carece de calles las que han sido reemplazadas por pasarelas y escaleras, que permiten la conectividad entre los habitantes de los diferentes sectores. Es un pueblo enclavado en la falda de un cerro que cae directamente al mar, sin una planicie litoral, de manera que para construir habitaciones, oficinas y plazas es necesario emparejar el terreno disponible o instalar las casas sobre pilotes que permitan conseguir la horizontal o construir plataformas. El acceso al (o la salida del) pueblo se puede realizar por escaleras de gran longitud o por vía marítima, esta última es importante para trasladar mercadería y equipaje. En este último caso es necesario dar una vuelta por el fiordo y luego entrar al 
río Baker, hasta el aeródromo, que se ubica en sus riberas.

A pesar de ser una caleta no es una caleta pesquera, sino una caleta maderera, cuyo desarrollo se basa principalmente, en la explotación del Ciprés de las Guaitecas (Pilgerodendron uviferum) árbol nativo abundante en la zona, que tiene una madera muy resistente, de un olor aromático y de un hermoso color amarillo claro, que es el material obligado para construcción tanto en la comuna de Tortel, como también en toda la Región de Aisén. De esta madera están confeccionadas y con ella son también reparadas las pasarelas y escaleras de Tortel. Últimamente, han surgido Artesanos que utilizan este material para construir réplicas de objetos típicos de la región.

Caleta Tortel se encuentra ubicada en la desembocadura del caudaloso río Baker, es la capital de la comuna de Tortel, y tiene un relieve muy accidentado que por años permitió acceso únicamente por vía marítima, sólo en el año 2003 fue conectada a la Carreta Austral (Figura 1). Geográficamente consta de una zona archipelágica con islas, canales y estuarios, y otra, de escarpadas cordilleras coronadas por glaciares y cortadas por estrechos valles. Su vegetación nativa consta de bosques perennifolios y caducifolios, matorrales (primarios y secundarios) turbales esfagnosos pantanosos en tierras bajas, turbales pulvinados y graminosos en lugares altos y estepa alto-andina de brecillo. Su territorio no alcanza a la estepa patagónica. En su fauna destacan los huemules, zorros y aves.

Todo lo anterior hace de Tortel y su comuna, un hermoso e interesante lugar para una estadía turística.

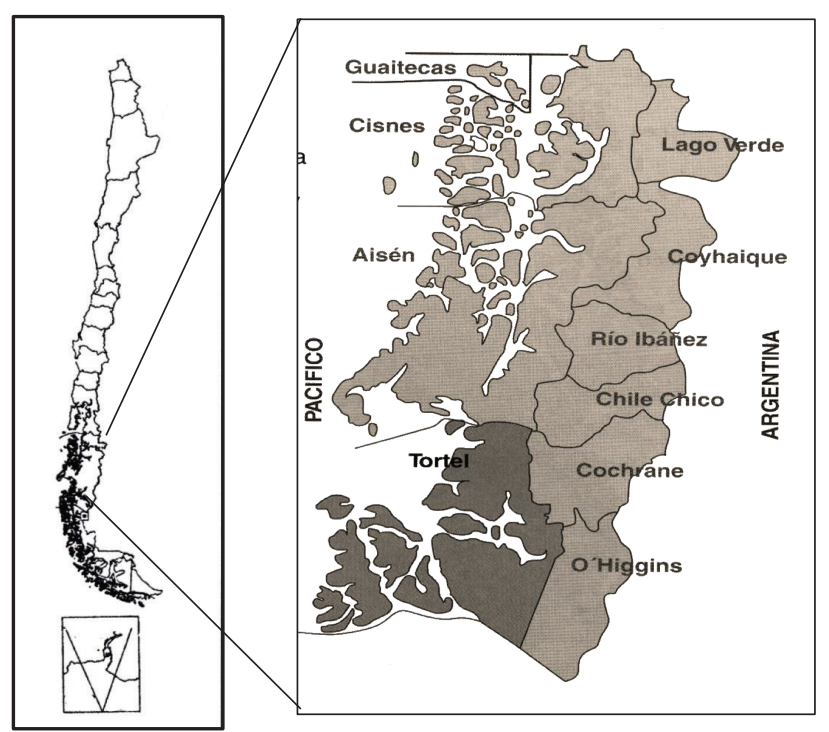

Figura 1. Comunas de la Región de Aisén (Chile). En el extremo inferior izquierdo se destaca la comuna de Tortel (Tomado y modificado de Servicio Nacional de Turismo: Guía turística de la Región de Aisén).

Figure 1. Communes of the Region of Aisen (Chile). In the lower left corner the commune Tortel is highlighted (Tourist Guide Aisen Region Taken and modified from National Tourism Service).
En ese contexto, el presente trabajo, tiene por objeto contribuir a un mejor conocimiento de la flora leñosa y de la vegetación de la Comuna de Tortel, recurso que permite atraer a los turistas, pero más que nada se trata dar a conocer este recurso para que pueda ser protegido y conservado. Como solo protegemos aquellos que conocemos, creemos que este estudio logrará su objetivo, para que los habitantes se preocupen de realizar una explotación de ellos en forma racional y sustentable.

\section{MATERIAL Y MÉTODOS}

En el año 2007, se realizaron prospecciones de flora y se levantaron censos de vegetación en la comuna de Tortel. Los censos de vegetación, levantados con la metodología fitosociológica del Sur de Europa (Knapp, 1984; Braun-Blanquet, 1979; Ramírez et al., 1997) permitieron conocer y clasificar la vegetación determinando comunidades (asociaciones) vegetales (Vidal et al., 2011) y establecer algunas de las series de degradación de la vegetación nativa (Ramírez et al., 2012; San Martín et al., 2014). Las colectas intensivas enriquecieron las listas florísticas de las tablas fitosociológicas con lo que se logró un conocimiento completo de la flora y no sólo de aquella leñosa (Ramírez et al., 2009).

Para el presente trabajo se seleccionaron las comunidades vegetales presentes en la comuna de Tortel que sirven de hábitats a la flora y de las cuales se hicieron descripciones y listas de las especies vegetales que las integran (Vidal et al., 2011). De la flora de la comuna se seleccionaron las especies leñosas, que fueron colectadas, secadas, determinadas y montadas en carpetas, material que fue depositado en el herbario VALD de la Universidad Austral de Chile en Valdivia. Para la determinación se utilizó la literatura taxonómica especializada (Muñoz, 1959; Vidal, 2007; Rodríguez et al., 2008; Álvarez et al., 2010) y para los grandes grupos de ellas no se consideró la clasificación actual por ser poco didáctica (Wink, 2006).

La flora leñosa de Tortel fue analizada en su clasificación taxonómica, origen y forma de crecimiento (Moore, 1982; Vidal, 2007). Se estudió la riqueza en especies de los géneros y familias presentes en la clasificación. El origen de las especies fue tomado de Zuloaga et al. (2008) y para la determinación de formas de crecimiento de las especies leñosas se utilizó la clave de Mueller-Dombois y Ellenberg (1974), complementada con las indicaciones de Rodríguez et al. (2008). Como árbol se consideraron las plantas leñosas con un solo tronco erguido que se ramifica en altura, como arbustos aquellas plantas leñosas con varios tallos que nacen desde un lignotuber, tallo corto con yemas enterrado en el suelo. En este caso los tallos aéreos son de vida más corta que el lignotuber (Ramírez et al., 1988). Como un tipo de planta leñosa diferente se consideró el único helecho arborescente presente. Además, se encontraron lianas o trepadoras, con tallos volubles que se enrollan en el árbol que actúa de soporte (forófito) y 
subarbustos, es decir, plantas leñosas pequeñas que no sobrepasan los $50 \mathrm{~cm}$ de altura (Frey y Lösch, 2010).

Los arbustos se subdividieron en normales, que coinciden con la definición dada, separando aquellos grandes (mayores de $5 \mathrm{~m}$ de alto) de los pequeños (menos de $2 \mathrm{~m}$ de alto). También se separaron especies de bambúes con el tallo transformado en una caña nudosa y estranguladores, arbustos que trepan ahogando al huésped. Por último se distinguieron arbustos semitrepadores que trepan a pequeña altura sujetándose pasivamente al forófito.

Para los subarbustos se distinguieron 4 tipos: erguidos que se levantan del suelo, rastrero cuyos tallos reptan sobre el sustrato, trepadores que se sujetan a un forófito y parásitos que viven unidos a otras plantas leñosas, alimentándose del hospedante (Godoy et al., 2001). También se estudiaron los hábitats de las especies leñosas de la comuna de Tortel, es decir, las comunidades vegetales de las que forman parte.

Por último y teniendo a la vista el material de herbario, ejemplares frescos y fotografías de todas las especies vegetales leñosas se procedió a confeccionar una clave para determinar (identificar) dichas especies. Para ello se fueron agrupando por sus caracteres, primero en grandes grupos los que paulatinamente fueron reduciéndose en grupos menores hasta llegar a aislar cada especie (Ramírez et al., 1994; Ramírez et al., 2004). Este proceso de comparación y de agrupación se llevó posteriormente a una clave de determinación dicotómica que permite repetir el mismo proceso de agrupación hasta llegar a las especies aisladas, de manera que es posible reducir cada especie a un grupo aislado, donde queda determinada. La clave fue construida utilizando caracteres fáciles de observar y discriminar por un lego.

\section{RESULTADOS}

\section{Los recursos vegetacionales de la Comuna de Tortel}

Este trabajo presenta la flora leñosa de la Comuna de Tortel, en la Región de Aisén Chile, que está integrada por árboles arbustos, subarbustos, parásitos y lianas que tienen lugar de vida en determinados hábitats. Estos hábitats se identifican con la vegetación, es decir, con las comunidades vegetales que forman el paisaje de la comuna, y que corresponden a las que a continuación se describen y cuya distribución en el paisaje se representa esquemáticamente en la Figura 2.

\section{Bosque de coigüe de Chiloé: Bosque chilote, Luzuriago-Nothofagetum nitidae (Amigo, Ramírez, Quintanilla, 2004).}

El bosque de coigüe de Chiloé es el bosque perennifolio más exuberante de toda el área estudiada, es muy abundante en tierras bajas. Se encuentra formando un cinturón continuo desde la orilla de los ríos, lagos y fior-

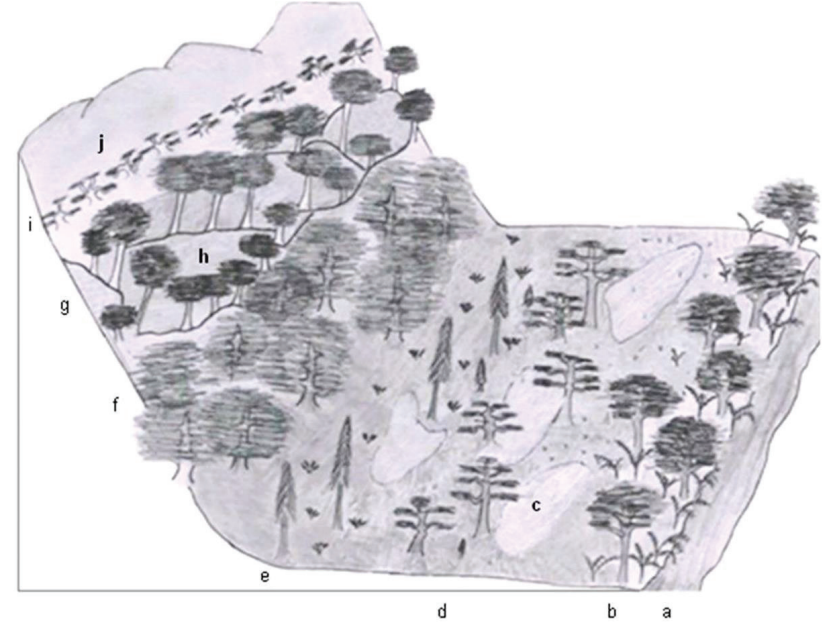

Figura 2. Perfil vegetacional esquemático en un gradiente altitudinal hipotético en la comuna de Tortel. $\mathrm{a}=$ río Baker, $\mathrm{b}=$ Bosque de Coihue, $\mathrm{c}=$ Turbera esfagnosa, $\mathrm{d}=$ Bosque de Ñire, $\mathrm{e}=$ Cipresal, $\mathrm{f}=$ Bosque chilote, $\mathrm{g}=$ Bosque magallánico perennifolio, $\mathrm{h}=$ Turbera pulvinada y graminosa, $\mathrm{i}=$ Krummholz de Lenga, $\mathrm{j}=$ Estepa de altura.

Figure 2. Vegetational draft along an hypothetical altitudinal gradient in the communen of Tortel. $\mathrm{a}=$ Baker river, $\mathrm{b}=$ coihue forest, $\mathrm{c}=$ Sphagnum peat bog, $\mathrm{d}=$ ñire forest,$\quad \mathrm{e}=$ cipresal, $\mathrm{f}=$ chilote forest, $\mathrm{g}=$ evergreen Magellanic forest, $\mathrm{h}=$ Pulvinate and gramineous peat bog, $\mathrm{i}=$ Krummholz of Lenga, $\mathrm{j}$ = high Andean Steppe.

dos hasta más o menos los $300 \mathrm{~m}$ de altitud. Ocasionalmente en lugares protegidos puede sobrepasar esa altitud. Se trata de un bosque mixto siempre verde, propio de climas muy húmedos de alta y permanente precipitación, con gran cantidad de especies y muy estratificado. El estrato arbóreo superior formado por el coigüe de Chiloé (Nothofagus nítida) puede sobrepasar los $30 \mathrm{~m}$. En un nivel más bajo aparecen Mirtáceas, canelo, tineo y mañío macho. En el sotobosque arbustivo abundan chilco, corcolén y varias especies de ñipas o siete camisas, arbustos de hasta $4 \mathrm{~m}$ de altura. En estratos inferiores, existen helechos de gran tamaño, como la palmita (Blechnum magellanicum), por ejemplo, además el piso está cubierto por un estrato muscinal donde domina el musgo pinito (Dendroligotrichum dendroides). Al ser destruido este bosque es reemplazado por un matorral de chilco (Fuchsia magellanica), zarzaparrilla (Ribes magellanicum) y nalca (Gunnera tinctoria) muy tupido.

\section{Bosque de coigüe de Magallanes: Bosque magallánico perennifolio, Nothofagetum betuloidis (Oberdorfer, 1960).}

Bosque mixto, siempre verde, con un abundante sotobosque de musgos, arbustos y subarbustos, aunque con menos especies que el anterior. Tiene una altura de entre 15 y 20 m y crece entre los 300 y $600 \mathrm{~m}$ de altitud, a mayor altura pierde tamaño y se presenta como un matorral acha- 
parrado (Krummholz de coigüe de Magallanes), ocupando preferentemente las exposiciones Norte (ecuatoriales) que son más cálidas. Crece sobre suelo orgánico delgado que descansa sobre un sustrato rocoso. Suele aparecer a menores altitudes, pero creciendo en lugares turbosos. A media altura en las montañas tiene una distribución reticulada que sigue la dirección de las quebradas donde crece, con mayor protección contra el viento. En este bosque abundan el coigüe de Magallanes (Nothofagus betuloides), el taique (Desfontainia fulgens), la chaura (Gaultheria mucronata), el mañío macho (Podocarpus nubigena), el canelo (Drimys winteri) y el michay (Berberis darwinii), entre otros.

\section{Bosque de coigüe: Bosque de Coihue puro, bosque de coigüe y colihue, Nothofagetum dombeyii (Oberdorfer, 1960).}

Bosque siempre verde, dominados ampliamente por el coigüe (Nothofagus dombeyi), de lugares cálidos y secos en menor altitud. Tiene una distribución lineal siguiendo las riberas más altas, rocosas y secas del río Baker, especialmente. En islotes y penínsulas de este río suele hacerse abundante. Su altura máxima no supera los $20 \mathrm{~m}$. Crece sobre suelo delgado, algo arenoso. El estrato arbóreo está ocupado exclusivamente por el coigüe. Por ser un bosque siempre verde muy tupido que no permite la penetración de la luz, el estrato herbáceo está casi ausente, con la única excepción de la abundancia de punke (Blechnum penna-marina). En el sotobosque destacan: colihue (Chusquea culeou), chaura grande (Gaultheria phyllireifolia), calafate (Berberis microphylla), michay y orocoipo (Myoschilos oblonga). Estos bosques, al ser destruidos, son reemplazados por un matorral secundario de chaura grande, muy rico en especies.

Bosque de ñire y colihue: Bosque de Ñire en Ñadi, Chusqueo-Nothofagetum antarcticae (Vidal et al., 2011).

Es un bosque caducifolio mixto, pero dominado por ñire (Nothofagus antarctica), que creciendo con forma arbórea, alcanza hasta $8 \mathrm{~m}$ de altura, acompañado de colihue (Chusquea culeou). Se presenta en bajas altitudes, en depresiones algo turbosas, pero con escasa inclinación y ondulación. En su estado prístino el suelo está cubierto del musgo pon-pon (Sphagnum magellanicum) y cuando en años húmedos este prolifera mucho, ahoga las especies más altas, dando origen a una turbera esfagnosa, constituyendo así la etapa previa a la formación de estas turberas. Normalmente son utilizados como silvopastoreo lo que provoca una marcada ondulación del sustrato blando y una proliferación de especies arbustivas espinosas, especialmente michay y calafate por la compactación del suelo y que al desaparecer la presión de pastoreo, suele transformarse en un matorral de calafate. En este estado de alta intervención aparecen malezas de origen europeo, tales como pasto dulce (Holcus lanatus), trébol blanco
(Trifolium repens) y diente de león (Taraxacum officinale). Las especies dominantes son ñire, colihue, punke, chapel (Escallonia virgata) y notro (Embothrium coccineum).

Bosque de ciprés de las Guaitecas: Bosque de ciprés, cipresal, Empetro-Pilgerodendronetum uviferae (Vidal et al., 2011).

Los Cipresales son bosques de poca altura cuyos rodales, generalmente pequeños, aparecen en zonas ecotonales (de borde) o en turberas, especialmente de pon-pon. El estrato superior raramente supera los $6 \mathrm{~m} \mathrm{y}$ en el herbáceo abunda el Brecillo (Empetrum rubrum), junto a una gran diversidad de musgos. En turbales viejos de pon-pon llamados mallines colorados, suelen encontrarse gran cantidad de ejemplares muertos en pie del ciprés de la Guaitecas (Pilgerodendron uviferum), seguramente como resultado de un avance del musgo que ahoga los ejemplares del árbol. Esto corrobora el origen secundario las turberas de pon-pon, que se formarían en lugares donde antiguamente había cipresales.

\section{Matorral achaparrado de lenga: Matorral alto- andino de lenga, Krummholz de lenga, Empetro- Nothofagetum pumiliae (Vidal et al., 2011).}

Por la presencia de un clima muy húmedo y por ende, más cálido, en la comuna de Tortel casi no se encuentran bosques de lenga (Nothofagus pumilio), pero a mayor altitud, en y por sobre el límite del bosque, ésta especie aparece formando un matorral achaparrado, llamado "Krummholz" (del alemán: "tronco torcido") de lenga. Este matorral achaparrado se presenta por sobre el bosque de coigüe de Magallanes más a menos entre 600 y $700 \mathrm{~m}$ de altitud, ocupando exposiciones Sur (Polares) que son más frías. Se trata de un matorral achaparrado, tortuoso y muy denso, casi impenetrable, que yace sobre suelo rocoso, seco. La lenga, el arbusto dominante no supera los $2 \mathrm{~m}$ de altura y se presenta deformado por efecto del peso de la nieve y de la excesiva radiación. Acompañan a la especie dominante, el subarbusto murtilla o brecillo, chaura y el miñe-miñe (Rubus geoides).

\section{Estepa alto-andina de brecillo: Estepa arbustiva alto-andina. Senecio-Empetretum rubrae asoc, nova provisional.}

Por sobre los Matorrales achaparrados de lenga y de coigüe de Magallanes se forma una estepa subarbustiva dominada por brecillo, especie que es capaz de soportar una cubierta nival de larga duración. Estas estepas que crecen por sobre los 700 m de altitud, presentan escaso suelo orgánico, y se desarrollan sobre arena de origen volcánico. La especie dominante, Empetrum rubrum está acompañada de plantas pulviniformes (acojinadas) y de una pequeña chaura, Gaultheria pu- 
mila. Especies herbáceas son más escasas pero siempre están presentes, como por ejemplo Senecio triodon utilizado en el nombre científico de la comunidad.

Turbales esfagnosos de pon-pon: Turbal, Mallines colorados, Sphagnetum magellanicii (Pisano, 1977) y Turbera subarbustiva de ciprés enano, Lepidothamnietum fonkii asoc. nova provisional.

Las turberas esfagnosas son pantanos turbosos que se presentan en bajas altitudes, en terrenos planos de terrazas de río, que por carecer de drenaje acumulan el agua del suelo (turbales topogénicos), mantienen condiciones de saturación de agua y un anegamiento que sólo suele interrumpirse en los meses de veranos muy secos. El micro-relieve de estas turberas está formado por montículos secos y depresiones anegadas. El sustrato sobre el que descansan es turba, es decir, materia orgánica descompuesta del mismo musgo dominante, el pon-pon (Sphagnum magellanicum), esta turba suele superar $1 \mathrm{~m}$ de espesor. Normalmente, aparecen cubiertos con ciprés de las Guaitecas muertos, pero en pie, indicando un origen secundario, por el raleo de los bosques, que permite la proliferación del musgo pon-pon por la mayor disponibilidad de luz. Sobre los cojines de color rojizo del pon-pón se desarrollan el brecillo, el rocío de sol (Drosera uniflora), pequeña planta insectívora que indica falta de nutrientes minerales y ejemplares de ñires, ciprés de las Guaitecas y coigües de Magallanes de pequeño tamaño. Estas turberas están siendo estudiadas para tener un conocimiento que permita a futuro su explotación racional, ya que el musgo pon-pon es un importante recurso de exportación.

La turbera subarbustiva dominada por el ciprés enano (Lepidothamnus fonkii) denomina en forma provisoria como Lepidotamnietum fonkii, presenta gran afinidad florística y ecológica con la turbera esfagnosa y al parecer representaría un estadio terminal de la turbera de Sphagnum magellanicum. La especie dominante crece sobre una cubierta herbácea de musgos (incluido el musgo pon-pon) y hierbas en cojín y sobresalen en ella, pequeños ejemplares de ñire, coigüe de Magallanes, notro y ciprés de las Guaitecas, con aspecto de "Bonsai". El último suele incluso formar pequeños bosquetes.

Turbales pulvinados: Turberas, Turbera de Donatia, Drosero-Donatietum fascicularis (Ramírez, 1968).

Los turbales pulvinados son turberas de condiciones más secas, generalmente laderas o planicies de altura, ocasionalmente se presentan en depresiones de bajas altitudes, pero con buen drenaje. Estas turberas ombrogénicas se alimentan sólo del agua de lluvia que retienen en sus cojines. El sustrato de turba delgado (alrededor de $50 \mathrm{~cm}$ ) y rara vez presentan anegamiento, aunque si suelen presentar pequeñas depresiones que forman lagunas. En estas turberas domina Donatia fascicularis, acompañadas de otras hierbas pulviniformes tales como Astelia pumila, Tapeinia pumila y Gaimardia australis. También es posible encontrar las insectívoras llamadas rocío de sol (Drosera uniflora) y las violetas de pantano (Pinguicula antarctica). En ellas suele abundar el musgo Racomithrium lanuginosum.

\section{Turbales graminosos: "Campañas", Turbera de Cortaderia pilosa y Schoenus antarcticus, denominada Cortaderio. Schoenetum antarcticae asoc. nova. provisional.}

Los turbales graminosos son turberas de lugares altos, es decir a media altura en las montañas, que conviven con el Bosque de Coihue de Magallanes, formando un típico mosaico vegetacional reticulado. Las turberas graminosas ocupan las cumbres más secas, mientras que el bosque crece en las quebradas. El sustrato de turba es muy delgado y rara vez presentan anegamiento. Las especies dominantes son la gramínea Cortaderia pilosa y la Juncaceae, Schoenus antarcticus, acompañadas en un estrato bajo por plantas pulviniformes típicas de turberas pulvinadas, en ellas también se encuentran pequeños ejemplares de Nothofagus betuloides y de Embothrium coccineum.

\section{Los recursos florísticos leñosos de Tortel}

La flora leñosa de la comuna de Tortel está formada por 61 especies distribuidas en 40 géneros, 31 familia y 4 grupos: Dicotiledóneas, Monocotiledóneas, Gimnospermas y Helechos. El máximo de especies por género corresponde a 5 presentados por los géneros Escallonia y Nothofagus, los primeros importantes en matorrales primarios y secundarios y los segundos, como dominantes de bosques y matorrales nativos. Los géneros Baccharis y Berberis presentan 4 especies cada uno y Gaultheria y Misodendron 3 especies cada uno. Dos especies sólo presentan los géneros Amomyrtus y Maytenus. Por último hay 31 géneros que sólo presentaron una especie (Figura 3).

El máximo de especies por familia, que llegó a cinco, lo presentaron las Asteraceae, Escalloniaceae, Myrtaceae y Nothofagaceae, todas importantes como componentes de bosques y matorrales. Cuatro especies sólo presentó la familia Berberidaceae y con 3 especies aparecen las Ericaceae y Misodendraceae. Además, 7 familias presentaron 2 especies cada una y 17, solo una especie (Figura 4).

De las 61 especies leñosas de la flora de la comuna de Tortel 58 (95,08 \%) son nativas y sólo 3 (4,02 \%), introducidas: Rosa rubiginosa (rosa mosqueta), Salix fragilis (sauce) y Populus nigra (álamo). Estas no son plantas invasoras sino que crecen en lugares alterados por el hombre la primera, a orillas de los ríos, la segunda y cerca de las habitaciones humanas, la tercera. Las dos primeras se han asilvestrado, pero el álamo debe ser plantado y cultivado. Un resumen de la clasificación y características de la flora leñosa de Tortel se presenta en el Cuadro 1. 


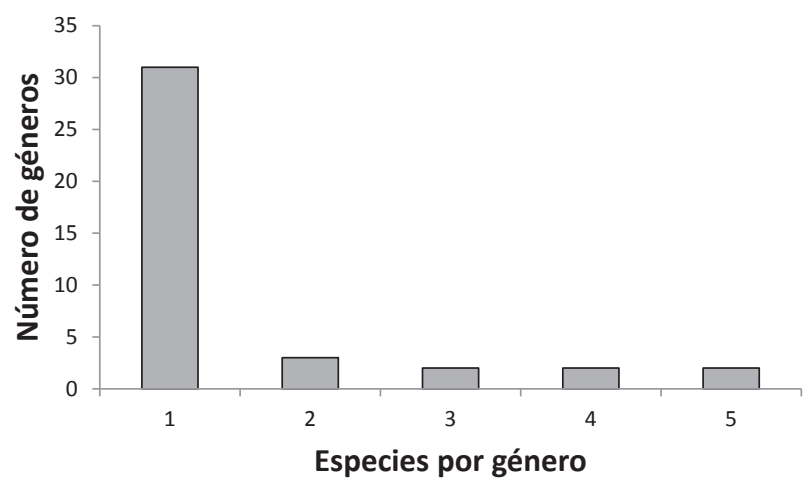

Figura 3. Número de géneros con distintos números de especies.

Figure 3. Number of genus with different numbers of species.

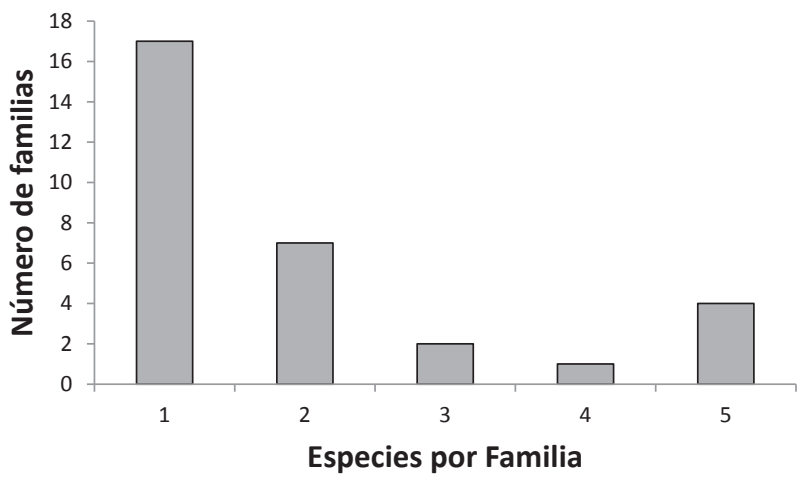

Figura 4. Número de familias con diferentes número de especies.

Figure 4. Number of families with different species number.

Cuadro 1. Caracterización de las especies vegetales leñosas de la comuna de Tortel. Se entrega nombre científico y autor, Grupo de vegetales (Gr) y Familia de la especie, nombre común en la Región de Aisén, Origen fitogeográfico (Or.) y Forma de crecimiento. Table 1. Caracterization of the woody plant species of the Tortel commune. Scientific name and autor, groups plants (Gr), Family of the species, commun name in the Aisen Region, Phytogeographical origin (Or.) and growth forms.

\begin{tabular}{|c|c|c|c|c|c|}
\hline Especies / Autor & Gr. & Familia & Nombre común & Or. & Forma de crecimiento \\
\hline Amomyrtus luma (Mol.) Legr. et Kaus. & $\mathrm{D}$ & Myrtaceae & Luma & $\mathrm{N}$ & Árbol \\
\hline Amomyrtus meli (Phil.) Legr. et Kaus. & $\mathrm{D}$ & Myrtaceae & Meli & $\mathrm{N}$ & Árbol \\
\hline Azara lanceolata Hook. f. & $\mathrm{D}$ & Flacourtiaceae & Corcolén, Aromo & $\mathrm{N}$ & Arbusto \\
\hline Baccharis magellanica (Lam.) Pers. & $\mathrm{D}$ & Asteraceae & Mosaiquillo & $\mathrm{N}$ & Subarbusto rastrero \\
\hline Baccharis nivalis (Weed.) Sch. Bip. ex Phil. & $\mathrm{D}$ & Asteraceae & Vautro chico & $\mathrm{N}$ & Subarbusto rastrero \\
\hline Baccharis obovata Hook. et Arn. & $\mathrm{D}$ & Asteraceae & Chilca, Baturro & $\mathrm{N}$ & Arbusto \\
\hline Baccharis patagonica Hook. et Arn. & $\mathrm{D}$ & Asteraceae & Chilquilla & $\mathrm{N}$ & Arbusto \\
\hline Berberis darwinii Hook. & $\mathrm{D}$ & Berberidaceae & Michay & $\mathrm{N}$ & Arbusto \\
\hline Berberis ilicifolia L. f. & $\mathrm{D}$ & Berberidaceae & Chelia, Mechay & $\mathrm{N}$ & Arbusto \\
\hline Berberis microphylla G. Forst. & $\mathrm{D}$ & Berberidaceae & Calafate & $\mathrm{N}$ & Arbusto \\
\hline Berberis serratodentata Lechl. & $\mathrm{D}$ & Berberidaceae & Michay & $\mathrm{N}$ & Arbusto \\
\hline Blechnum magellanicum (Desv,) Mett. & $\mathrm{H}$ & Blechnaceae & Palmerita, Catalapi & $\mathrm{N}$ & Helecho arborescente \\
\hline Caldcluvia paniculata (Cav.) D. Don. & $\mathrm{D}$ & Cunoniaceae & Tiaca, Quiaca & $\mathrm{N}$ & Árbol \\
\hline Campsidium valdivianum (Phil.) Skottsb. & $\mathrm{D}$ & Bignoniaceae & Voqui bejuco & $\mathrm{N}$ & Liana \\
\hline Chilliotrichum diffusum (G. Forst.) Kuntze & $\mathrm{D}$ & Asteraceae & Mata verde & $\mathrm{N}$ & Arbusto \\
\hline Chusquea culeou E. Desv. & M & Poaceae & Colihue & $\mathrm{N}$ & Arbusto bambúseo \\
\hline Colletia hystrix Clos. & $\mathrm{D}$ & Rhamnaceae & Yaqui, Yaquil & $\mathrm{N}$ & Arbusto grande \\
\hline Desfontainia fulgens D. Don & $\mathrm{D}$ & Desfontainiaceae & Taique & $\mathrm{N}$ & Arbusto \\
\hline Discaria chacaye (G. Don) Tortosa & $\mathrm{D}$ & Rhamnaceae & Chacay & $\mathrm{N}$ & Arbusto grande \\
\hline Drimys winteri R. Forst. et G. Forst. & $\mathrm{D}$ & Winteraceae & Canelo, Foige & $\mathrm{N}$ & Árbol \\
\hline Embothrium coccineum Forst. & $\mathrm{D}$ & Proteaceae & Notro, Ciruelillo & $\mathrm{N}$ & Árbol \\
\hline Empetrum rubrum Vahl.ex Willd. & $\mathrm{D}$ & Empetraceae & Brecillo, Murtilla & $\mathrm{N}$ & Subarbusto erguido \\
\hline Escallonia alpina Poepp. ex Dc. & $\mathrm{D}$ & Escalloniaceae & Siete camisas & $\mathrm{N}$ & Arbusto \\
\hline Escallonia rosea Griseb. & $\mathrm{D}$ & Escalloniaceae & Ñipa rosada & $\mathrm{N}$ & Arbusto \\
\hline
\end{tabular}




\begin{tabular}{|c|c|c|c|c|c|}
\hline Escallonia serrata $\mathrm{Sm}$. & $\mathrm{D}$ & Escalloniaceae & Ñipa & $\mathrm{N}$ & Arbusto \\
\hline Escallonia rubra (Ruiz et Pav.) Pers. & $\mathrm{D}$ & Escalloniaceae & Siete camisas & $\mathrm{N}$ & Arbusto \\
\hline Escallonia virgata Griseb. & $\mathrm{D}$ & Escalloniaceae & Chapel, Meki & $\mathrm{N}$ & Arbusto \\
\hline Fuchsia magellanica Lam. & $\mathrm{D}$ & Onagraceae & Chilco & $\mathrm{N}$ & Arbusto \\
\hline Gaultheria antarctica Hook. f. & $\mathrm{D}$ & Ericaceae & Chaurilla & $\mathrm{N}$ & Subarbusto rastrero \\
\hline Gaultheria mucronata (L. f.) Hook. et Arn. & $\mathrm{D}$ & Ericaceae & Chaura, Murta & $\mathrm{N}$ & Subarbusto erguido \\
\hline Gaultheria phillyreifolia (Pers.) Sleumer & $\mathrm{D}$ & Ericaceae & Chaura grande & $\mathrm{N}$ & Arbusto \\
\hline Griselinia ruscifolia (Clos.) Ball. & $\mathrm{D}$ & Cornaceae & Yelmo, Lilinquen & $\mathrm{N}$ & Liana \\
\hline Lebetanthus myrsinites (Lam.) Dusén & $\mathrm{D}$ & Epacridaceae & Chaurilla & $\mathrm{N}$ & Arbusto semitrepador \\
\hline Lepidothamnus fonkii Phil. & G & Podocarpaceae & Ciprés enano & $\mathrm{N}$ & Subarbusto erguido \\
\hline Lomatia ferruginea (Cav.) R. Br. & $\mathrm{D}$ & Proteaceae & Fuinque, Huinque & $\mathrm{N}$ & Árbol pequeño \\
\hline $\begin{array}{l}\text { Luzuriaga marginata (Banks et sol. ex } \\
\text { Gaertn.) Benth. }\end{array}$ & M & Luzuriagaceae & Quilineja & $\mathrm{N}$ & Subarbusto trepador \\
\hline Maytenus disticha (Hook. f.) Urb. & $\mathrm{D}$ & Celastraceae & Racoma & $\mathrm{N}$ & Subarbusto \\
\hline Maytenus magellanica (Lam.) Hook. f. & $\mathrm{D}$ & Celastraceae & Leñadura & $\mathrm{N}$ & Árbol pequeño \\
\hline Misodendron angulatum Phil. & $\mathrm{D}$ & Misodendraceae & Injerto & $\mathrm{N}$ & Subarbusto parásito \\
\hline Misodendron linearifolium DC. & $\mathrm{D}$ & Misodendraceae & Huechu-lahuen & $\mathrm{N}$ & Subarbusto parásito \\
\hline Misodendron punctulatum Banks ex DC. & $\mathrm{D}$ & Misodendraceae & Farolito chino & $\mathrm{N}$ & Subarbusto parásito \\
\hline Mitraria coccinea Cav. & $\mathrm{D}$ & Gesneriaceae & Botellita & $\mathrm{N}$ & Arbusto semitrepador \\
\hline Myoschilos oblonga Ruiz et Pav. & $\mathrm{D}$ & Santalaceae & Orocoipo & $\mathrm{N}$ & Arbusto pequeño \\
\hline Myrceugenia ovata (Hook. et Arn.) Berg. & $\mathrm{D}$ & Myrtaceae & Huillipeta & $\mathrm{N}$ & Arbusto \\
\hline Myrteola nummularia (Poir.) Berg. & $\mathrm{D}$ & Myrtaceae & Huarapo & $\mathrm{N}$ & Subarbusto rastrero \\
\hline Nothofagus antarctica (G. Forst.) Oerst. & $\mathrm{D}$ & Nothofagaceae & Ñire, Ñirre & $\mathrm{N}$ & Arbusto / Árbol \\
\hline Nothofagus betuloides (Mirb.) Oerst. & $\mathrm{D}$ & Nothofagaceae & Coigüe de Magallanes & $\mathrm{N}$ & Árbol \\
\hline Nothofagus dombeyi (Mirb.) Oerts, & $\mathrm{D}$ & Nothofagaceae & Coigüe & $\mathrm{N}$ & Árbol \\
\hline Nothofagus nitida (Phil.) Krasser & $\mathrm{D}$ & Nothofagaceae & Coigüe de Chiloé & $\mathrm{N}$ & Árbol \\
\hline $\begin{array}{l}\text { Nothofagus pumilio (Poepp. et Endl.) } \\
\text { Krasser }\end{array}$ & $\mathrm{D}$ & Nothofagaceae & Lenga & $\mathrm{N}$ & Árbol / Arbusto \\
\hline Philesia magellanica J. F. Gmel. & M & Philesiaceae & Coicopihue & $\mathrm{N}$ & Arbusto semitrepador \\
\hline Pilgerodendron uviferum (D. Don) Florin & G & Cupressaceae & Ciprés de las Guaitecas & $\mathrm{N}$ & Árbol \\
\hline Podocarpus nubigena Lindl. & G & Podocarpaceae & Mañío macho & $\mathrm{N}$ & Árbol \\
\hline $\begin{array}{l}\text { Populus nigra L. var. italica (Moench.) } \\
\text { Koehne }\end{array}$ & $\mathrm{D}$ & Salicaceae & Alamo & I & Árbol \\
\hline Raukaua laetevirens (Gay) Frodin & $\mathrm{D}$ & Araliaceae & Sauco, Lloimén & $\mathrm{N}$ & Arbusto estrangulador \\
\hline Ribes magellanicum Poir. & $\mathrm{D}$ & Grossulariaceae & Zarzaparrilla & $\mathrm{N}$ & Arbusto \\
\hline Ribes trilobum Meyen & $\mathrm{D}$ & Grossulariaceae & Parrilla & $\mathrm{N}$ & Arbusto \\
\hline Rosa rubiginosa $\mathrm{L}$. & $\mathrm{D}$ & Rosaceae & Rosa mosqueta & I & Arbusto \\
\hline Salix fragilis L. & $\mathrm{D}$ & Salicaceae & Sauce & I & Árbol \\
\hline Tepualia stipularis (Hook. et Arn.) Griseb. & $\mathrm{D}$ & Myrtaceae & Tepu & $\mathrm{N}$ & Arbusto / Árbol \\
\hline Weinmannia trichosperma Cav. & $\mathrm{D}$ & Cunoniaceae & Tineo & $\mathrm{N}$ & Árbol \\
\hline
\end{tabular}

Abreviaturas: Gr. = grandes grupos de vegetales: $\mathrm{D}=$ Dicotiledóneas, $\mathrm{M}=$ Monocotiledóneas, $\mathrm{G}=$ Gimnospermas, $\mathrm{H}=$ Helechos; Or. = origen fitogeográfico: $\mathrm{N}$ = nativo, $\mathrm{I}$ = introducido.

Abreviaturas: Gr. = largest plant groups: $\mathrm{D}=$ Dicotiledons, $\mathrm{M}=$ Monocotiledons, $\mathrm{G}=$ Gimnosperms, $\mathrm{H}=$ Ferns; Or. = phyrogeographycal origin: $\mathrm{N}=$ native, $\mathrm{I}$ = foreings. 
Como era de esperar el mayor número de especies (54) corresponde a las Dicotiledóneas en sentido amplio, es decir, incluyendo Angiospermas basales y Magnoliales (Cuadro 2). Monocotiledóneas y Gimnospermas presentan 3 especies cada una (Chusquea coleou, Luzuriaga marginata y Philesia magellanica las primeras y Lepidothamnus fonkii, Pilgerodendron uviferum y Podocarpus nubigena, las segundas), lo que se corresponde con el hecho de que en Monocotiledóneas abundan las hierbas y con las pocas Gimnospermas presentes en Chile. Sólo se presentó un helecho leñoso, Blechnum magellanicum que semejan una pequeña palmera $>1 \mathrm{~m}$ de altura.

La forma de crecimiento dominante fueron los arbustos con 28 especies y un $45,9 \%$ de la flora total. Le siguen la forma árbol con 15 especies y 24,59 \% y la de subarbustos con 12 especies y 19,67 \% (Cuadro 3). Las formas de crecimiento especializadas son más escasas. Entre estas últimas figuran tres especies que pueden crecer como árbol o como arbusto, se trata de Nothofagus antarctica, Tepualia stipularis y Nothofagus pumilio. Además se presentan dos lianas: Campsidium valdivianum y Griselinia ruscifolia, ambas propias de los bosques de coigüe de Chiloé. Con una sola especie aparece el helecho arborescente Blechnum magellanicum.

Entre la forma de crecimiento arbusto, figuran 20 especies que son normales, es decir, que crecen entre 2 y $5 \mathrm{~m}$ de altura (Cuadro 4). Arbustos grandes que superan los $5 \mathrm{~m}$ de altura hay dos especies, Colletia histryx y Discaria chacaye y como arbustos pequeño $<2 \mathrm{~m}$ aparece sólo Myoschilos oblonga. Además, se colectaron un arbusto bambúseo, Chusquea coleou el Colihue y un estrangulador, Raukaua laetevirens, esta último ahoga árboles abrazándolos con sus tallos volubles. También figuran en esta forma de crecimiento tres arbustos semitrepadores: Lebethantus myrsinites, Mitraria coccinea y Philesia magellanica.

Los subarbustos presentaron 4 formas: erguidos, rastreros, parásitos y trepadores. El primer tipo que se puede considerar normal, presentó 4 especies: Maytenus disticha, Empetrum rubrum, Gaultheria mucronata y Lepidothamnus fonkii. Los rastreros que yacen sobre la superficie del suelo, también presentaron igual número: Baccharis magellanica, B. nivalis, Gaultheria antarctica y Myrteola nummularia. Los 3 subarbustos parásitos corresponden a: Misodendron angulatum, $M$. linearifolium y M. punctulatum, todos parásitos de árboles del género Nothofagus, los coihues, la lenga y el ñire. Con una sola especie (Luzuriaga marginata) figuran los subarbustos semitrepadores (Cuadro 5).

La flora leñosa descrita caracteriza las comunidades vegetales que crecen en la comuna de Tortel. El Cuadro 6 muestra su distribución en las diferentes comunidades descritas anteriormente. La especie con presencia (frecuencia) en más comunidades fue Drimys winteri que apareció en 5 de ellas, siguiéndole muy de
Cuadro 2. Distribución de la flora leñosa de la comuna de Tortel en grandes grupos de vegetales.

Table 2. Distribution of the woody flora of the Tortel commune in largest groups of plants.

\begin{tabular}{lcc}
\hline Grupo & Especies & Porcentaje \\
\hline Dicotiledóneas & 54 & 88,52 \\
Monocotiledóneas & 3 & 4,92 \\
Gimnospermas & 3 & 4,92 \\
Helechos & 1 & 1,64 \\
\hline Total & 61 & 100 \\
\hline
\end{tabular}

Cuadro 3. Número de especies leñosas por forma de crecimiento.

Table 3. Number of woody species by growths forms.

\begin{tabular}{lcc}
\hline Forma de Crecimiento & Especies & Porcentaje \\
\hline Árbol & 15 & 24,59 \\
Árbol / Arbusto & 3 & 4,92 \\
Arbusto & 28 & 45,90 \\
Helecho arborescente & 1 & 1,64 \\
Liana & 2 & 3,28 \\
Subarbusto & 12 & 19,67 \\
\hline Total & 61 & 100 \\
\hline
\end{tabular}

Cuadro 4. Número de especies por tipos de formas de crecimiento en arbustos.

Table 4. Scrub number of woody species by types of growths form from shrubs.

\begin{tabular}{lcc}
\hline Forma de arbusto & Especies & Porcentaje \\
\hline Normal & 20 & 71,43 \\
Grandes $(>5 \mathrm{~m})$ & 2 & 7,14 \\
Pequeños $(<2 \mathrm{~m})$ & 1 & 3,57 \\
Bambú & 1 & 3,57 \\
Estrangulador & 1 & 3,57 \\
Semitrepador & 3 & 10,72 \\
\hline Total & 28 & 100 \\
\hline
\end{tabular}

Cuadro 5. Número de especies por tipos de formas de crecimiento en subarbustos.

Table 5. Number of species by grows forms types from hemishrubs.

\begin{tabular}{lcc}
\hline Forma de subarbusto & Especies & Porcentaje \\
\hline Erguido & 4 & 33,33 \\
Parásito & 3 & 25,00 \\
Rastrero & 4 & 33,33 \\
Trepador & 1 & 8,33 \\
\hline Total & 12 & 99,99 \\
\hline
\end{tabular}


Cuadro 6. Presencia de especies vegetales leñosas en las distintas comunidades vegetales existentes en la comuna de Tortel, Región de Aisén, Chile.

Table 6. Presence of the woody plant species by different plant communities in the Tortel commune, Aisen Region, Chile.

\begin{tabular}{|c|c|c|c|c|c|c|c|c|c|c|c|}
\hline Especies & $\mathrm{BCh}$ & BCM & $\mathrm{BC}$ & BÑCh & C & $\mathrm{K}$ & $\mathrm{Ea}$ & $\mathrm{Te}$ & $\mathrm{Tp}$ & $\mathrm{Hr}$ & Fr. \\
\hline Drimys winteri & $\mathrm{X}$ & $\mathrm{X}$ & & $\mathrm{x}$ & & & & $\mathrm{x}$ & $\mathrm{X}$ & & 5 \\
\hline Nothofagus antarctica & & & & $\mathrm{x}$ & & $\mathrm{X}$ & & $\mathrm{x}$ & $\mathrm{X}$ & & 4 \\
\hline Chusquea coleou & $\mathrm{X}$ & & $\mathrm{X}$ & $\mathrm{x}$ & & & & & & & 3 \\
\hline Tepualia stipularis & $\mathrm{X}$ & & & $\mathrm{X}$ & $\mathrm{X}$ & & & & & & 3 \\
\hline Embothrium coccineum & & & $\mathrm{X}$ & & & $\mathrm{X}$ & & & $\mathrm{X}$ & & 3 \\
\hline Desfontainia fulgens & $\mathrm{X}$ & $\mathrm{X}$ & & & & & & & & & 2 \\
\hline Blechnum magellanicum & $\mathrm{X}$ & $\mathrm{X}$ & & & & & & & & & 2 \\
\hline Campsidium valdivianum & $\mathrm{X}$ & $\mathrm{X}$ & & & & & & & & & 2 \\
\hline Misodendron angulatum & $\mathrm{X}$ & $\mathrm{X}$ & & & & & & & & & 2 \\
\hline Philesia magellanica & $\mathrm{X}$ & & & & $\mathrm{x}$ & & & & & & 2 \\
\hline Myrceugenia ovata & & $\mathrm{X}$ & & & & $\mathrm{X}$ & & & & & 2 \\
\hline Nothofagus betuloides & & $\mathrm{X}$ & & & & & & & $\mathrm{X}$ & & 2 \\
\hline Discaria chacaye & & & $\mathrm{x}$ & & $\mathrm{x}$ & & & & & & 2 \\
\hline Escallonia virgata & & & & $\mathrm{X}$ & & & & $\mathrm{x}$ & & & 2 \\
\hline Misodendron linearifolium & & & & $\mathrm{X}$ & & $\mathrm{X}$ & & & & & 2 \\
\hline Myoschilos oblonga & & & & $\mathrm{X}$ & & $\mathrm{x}$ & & & & & 2 \\
\hline Pilgerodendron uviferum & & & & & $\mathrm{X}$ & & & $\mathrm{X}$ & & & 2 \\
\hline Baccharis magellanica & & & & & & $\mathrm{X}$ & $\mathrm{x}$ & & & & 2 \\
\hline Empetrum rubrum & & & & & & $\mathrm{x}$ & $\mathrm{x}$ & & & & 2 \\
\hline Chilliotrichum diffusum & & & & & & & & $\mathrm{X}$ & $\mathrm{X}$ & & 2 \\
\hline Myrteola nummularia & & & & & & & & $\mathrm{X}$ & $\mathrm{X}$ & & 2 \\
\hline Amomyrtus luma & $\mathrm{X}$ & & & & & & & & & & 1 \\
\hline Amomyrtus meli & $\mathrm{X}$ & & & & & & & & & & 1 \\
\hline Azara lanceolata & $\mathrm{X}$ & & & & & & & & & & 1 \\
\hline Caldcluvia paniculata & $\mathrm{X}$ & & & & & & & & & & 1 \\
\hline Fuchsia magellanica & $\mathrm{X}$ & & & & & & & & & & 1 \\
\hline Gaultheria phillyreifolia & $\mathrm{X}$ & & & & & & & & & & 1 \\
\hline Griselinia ruscifolia & $\mathrm{X}$ & & & & & & & & & & 1 \\
\hline Lomatia ferruginea & $\mathrm{X}$ & & & & & & & & & & 1 \\
\hline Luzuriaga marginata & $\mathrm{X}$ & & & & & & & & & & 1 \\
\hline Nothofagus nitida & $\mathrm{X}$ & & & & & & & & & & 1 \\
\hline Mitraria coccinea & $\mathrm{x}$ & & & & & & & & & & 1 \\
\hline Maytenus magellanica & $\mathrm{X}$ & & & & & & & & & & 1 \\
\hline Raukaua laetevirens & $\mathrm{x}$ & & & & & & & & & & 1 \\
\hline Ribes magellanicum & $\mathrm{X}$ & & & & & & & & & & 1 \\
\hline Weinmannia trichosperma & $\mathrm{x}$ & & & & & & & & & & 1 \\
\hline Podocarpus nubigena & $\mathrm{x}$ & & & & & & & & & & 1 \\
\hline Lebetanthus myrsinites & & $\mathrm{X}$ & & & & & & & & & 1 \\
\hline
\end{tabular}




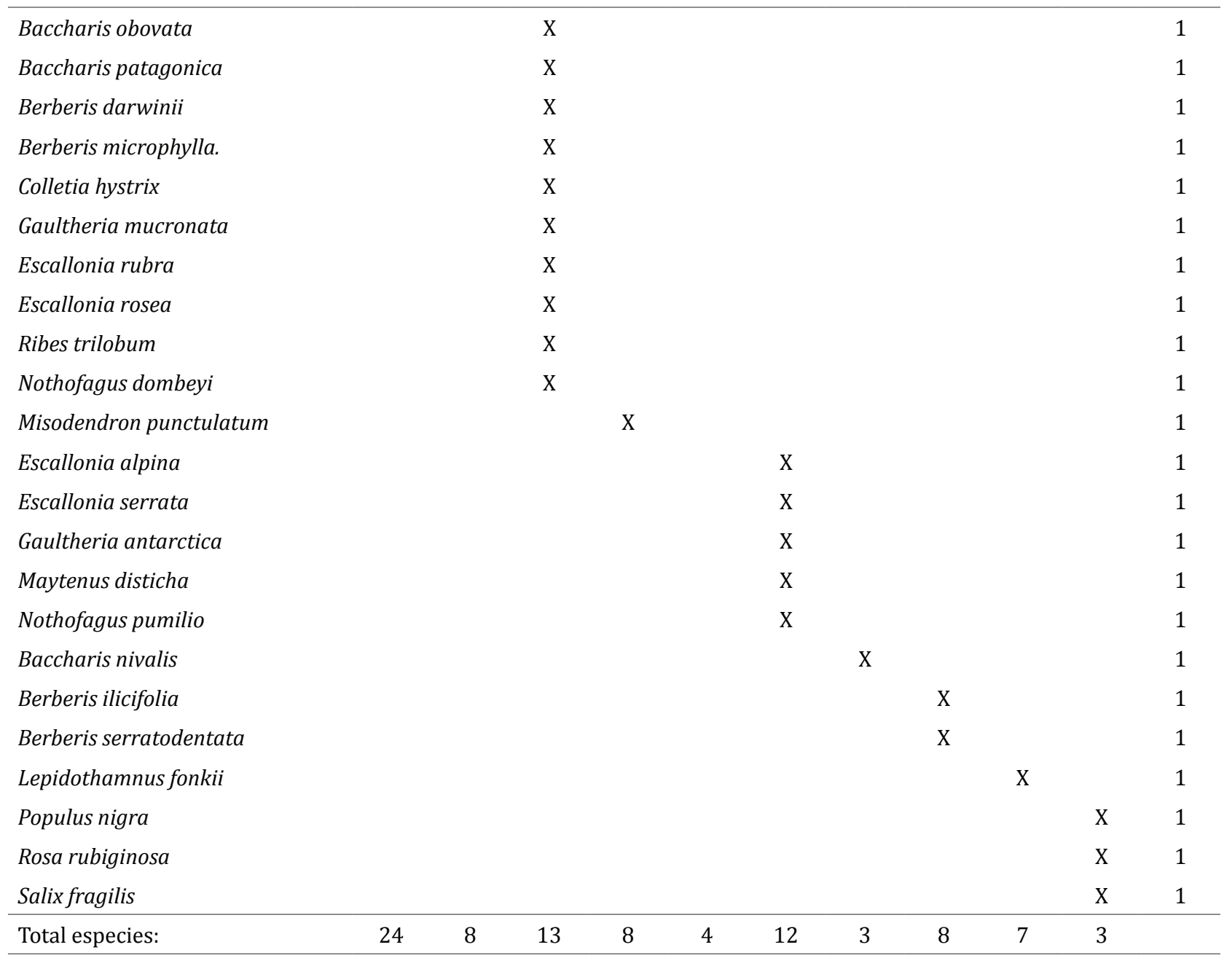

Abreviaturas: $\mathrm{BCH}=$ bosque chilote, $\mathrm{BCM}=$ bosque de coigüe de Magallanes, $\mathrm{BC}=$ bosque de coigüe, $\mathrm{BN} C \mathrm{Ch}=$ bosque de ñire y coligüe, $\mathrm{C}=$ cipre$\mathrm{sal}, \mathrm{K}=$ matorral de lenga, $\mathrm{Ea}=$ estepa alto-andina, $\mathrm{Te}=$ turbera esfagnosa, $\mathrm{Tp}=$ turbera pulvinada, $\mathrm{HA}=$ hábitat ruderal, $\mathrm{Fr}=\mathrm{frecuencia}$. La letra $\mathrm{X}$ indica presencia.

Abreviations: $\mathrm{BCH}=$ chilote forest, $\mathrm{BCM}=$ coigüe de Magallanes forest, $\mathrm{BC}=$ coigüe forest, $\mathrm{BN} C \mathrm{Ch}=$ ñire and coligüe forest, $\mathrm{C}=$ cipresal, $\mathrm{K}=$ matorral de lenga, $\mathrm{Ea}=$ high andean steppe, $\mathrm{Te}=$ sphagnum bog, $\mathrm{Tp}=$ pulvinate bog, $\mathrm{HA}=$ ruderal habitat, $\mathrm{Fr}=$ frequency.

The $\mathrm{X}$ letter indicated presence.

cerca Nothofagus antarctica presente en 4 comunidades. Con frecuencia 3 aparecen Chusquea culeou y Tepualia stipularis. Además hay 16 (26,23\%) especies con frecuencia 2 y $40(55,57 \%)$ que sólo se presentan en una comunidad determinada, es decir son exclusivas de ellas. Esta distribución indica que la vegetación de la comuna de Tortel es muy diversa en cuanto a especies leñosas, es decir, cada comunidad tiene su individualidad con respecto a ellas (Figura 5).

$\mathrm{Al}$ hacer un análisis vertical del Cuadro 6 se observa que la cantidad de especies leñosas por comunidad es muy variable siendo en general mayor en bosques y matorrales y menor en turberas. El promedio de especies por comunidad alcanzó a 9 con un máximo de 24 en el bosque de coigüe de Chiloé y un mínimo de 3 en el matorral achaparado (Krumholz) de lenga. Las comunidades ruderales con leñosas nativas también pre-

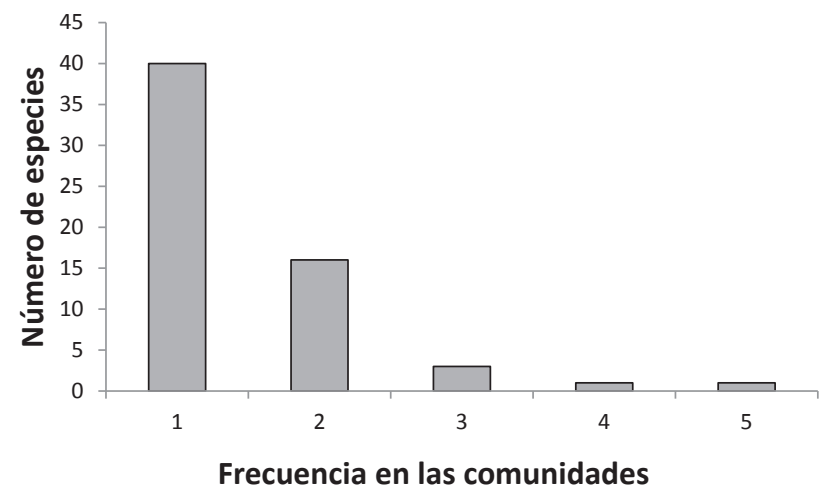

Figura 5. Presencia (frecuencia) de especies leñosas en las comunidades vegetales de la comuna de Tortel.

Figure 5. Presence (frequency) of the woody species in the plant communities of the Tortel commune. 
sentan en total 3 especies diferentes, pero dos de ellas (Rosa rubiginosa y Salix fragilis) presentan su propia comunidad y los álamos, son plantados.

\section{Determinación (identificación) de las plantas leñosas de la comuna de Tortel}

Cuando uno encuentra una planta que no conoce y no tiene en las cercanías a un especialista a quien preguntarle su nombre, se puede recurrir a las llamadas "claves" o "llaves", para identificar la especie a que pertenece la planta-problema. De acuerdo a lo anterior, podríamos definir una clave como "un instrumento para determinar o identificar plantas". Con ellas es posible ubicar la especie a que pertenece el ejemplar desconocido, asignarle un nombre (determinarla) y lo que es más importante, darle un lugar en el sistema de clasificación del Reino Vegetal (clasificarla), es decir, establecer a que Familia, a que Orden y a que Clase del Reino Vegetal pertenece.

Las claves operan en base a la confrontación de la especie problema con pares de caracteres contrastantes y excluyentes, es decir, caracteres opuestos que no se presentan juntos en la planta. De manera que la planta sólo puede presentar uno de estos, eliminando así, la posibilidad del otro. Siempre que se acepte una proposición del par de características contrastantes, debemos remitirnos a la indicación pertinente ubicada en el margen derecho de la página. Cuando allí figure un número significa que debemos avanzar en la clave, buscando el par de caracteres contrastantes correspondientes a ese número y someter allí, nuevamente a comparación, nuestra especie-problema. Cuando en el borde derecho de la página al final de la última proposición aceptada aparecen dos palabras, que corresponden a un nombre científico, significa que hemos llegado a determinar (identificar) la especie. No siempre es fácil determinar una especie, ya que aunque se cuente con la clave adecuada a veces debemos decidir entre características que no pueden diferenciarse claramente. A veces es necesario verificar la identidad del vegetal, comparándolo con una descripción o una lámina de él o consultando un herbario. Como en Chile existen más de 5000 especies de plantas, no es posible tener una clave para todas juntas, por lo que se construyen claves parciales que sirven para identificar las plantas de una determinada región o de un determinado grupo de vegetales. La clave que presentamos aquí sólo sirve para identificar las especies de plantas leñosas (de tallo duro, con madera) que crecen en la comuna de Tortel, en la Región de Aisén del General Carlos Ibáñez del Campo y está elaborada utilizando caracteres simples y fáciles de observar por un lego en terreno. Para determinar una planta nos basta con tener en nuestras manos una rama de ella, que ojalá tenga flores y/o frutos.

\section{Clave de campo para la flora leñosa de la comuna de Tortel.}

\begin{tabular}{|c|c|c|}
\hline $1 \mathrm{a}$ & 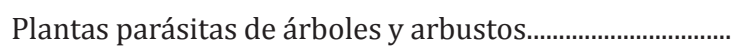 & 2 \\
\hline $1 \mathrm{~b}$ & 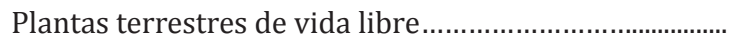 & 4 \\
\hline $2 \mathrm{a}$ & 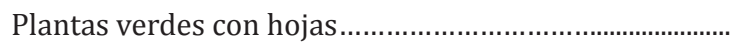 & Misodendron linearifolium \\
\hline $2 b$ & 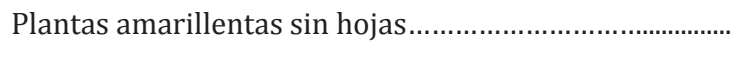 & 3 \\
\hline $3 a$ & 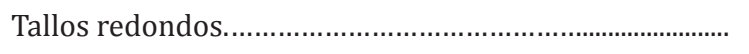 & Misodendron punctulatum \\
\hline $3 b$ & 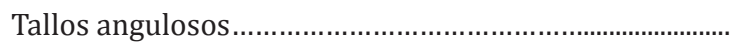 & Misodendon angulatum \\
\hline $4 \mathrm{a}$ & 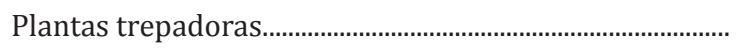 & 5 \\
\hline $4 b$ & 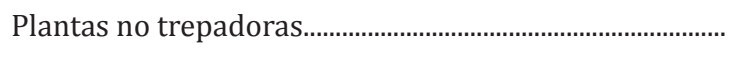 & 9 \\
\hline $5 a$ & 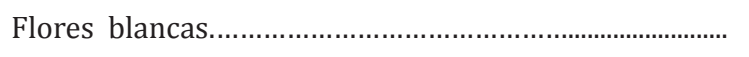 & Luzuriaga marginata \\
\hline $5 b$ & 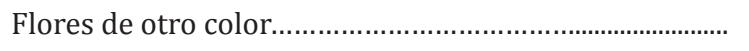 & 6 \\
\hline $6 a$ & 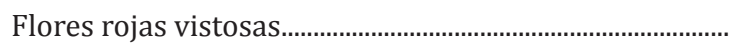 & 8 \\
\hline $6 b$ & Flores verde-amarillentas poco aparentes............................ & 7 \\
\hline $7 a$ & Hojas digitadas, ápice foliar de 1 punta.............................. & Raukaua laetevirens \\
\hline $7 b$ & Hojas simples, ápice dividido en 3 puntas......................... & Griselinia ruscifolia \\
\hline $8 \mathrm{a}$ & 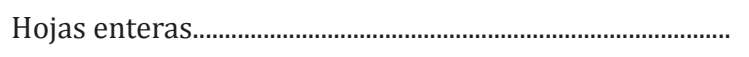 & Mitraria coccinea \\
\hline $8 b$ & 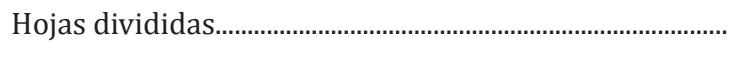 & Campsidium valdivianum \\
\hline $9 \mathrm{a}$ & Árboles, con un sólo tronco ramificados en altura........... & 10 \\
\hline $9 b$ & Arbustos, con varios troncos desde la base ......................... & 27 \\
\hline $10 \mathrm{a}$ & 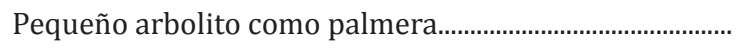 & Blechnum magellanicum \\
\hline $10 \mathrm{~b}$ & 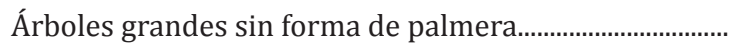 & 11 \\
\hline
\end{tabular}




\begin{tabular}{|c|c|c|}
\hline $11 \mathrm{a}$ & 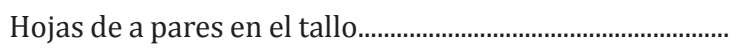 & 12 \\
\hline $11 b$ & 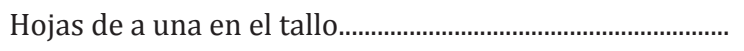 & 15 \\
\hline $12 \mathrm{a}$ & 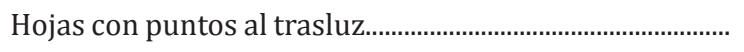 & Tepualia stipularis \\
\hline $12 b$ & 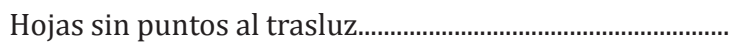 & 13 \\
\hline $13 a$ & Hojas menores de $1 \mathrm{~cm}$ & Pilgerodendron uviferum \\
\hline $13 b$ & Hojas mayores de $1 \mathrm{~cm}$ & 14 \\
\hline $14 \mathrm{a}$ & 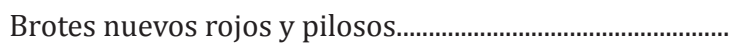 & Amomyrtus luma \\
\hline $14 \mathrm{~b}$ & 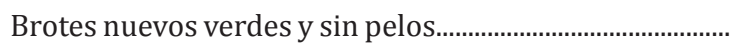 & Amomyrtus meli \\
\hline $15 \mathrm{a}$ & 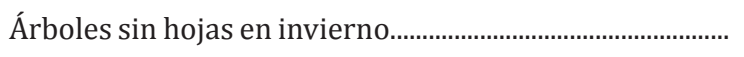 & 16 \\
\hline $15 b$ & 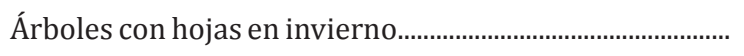 & 19 \\
\hline $16 \mathrm{a}$ & 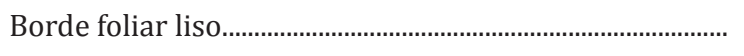 & Embothrium coccineum \\
\hline $16 \mathrm{~b}$ & 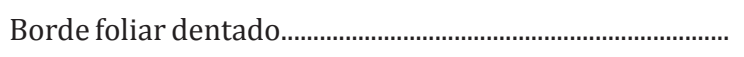 & 17 \\
\hline $17 \mathrm{a}$ & 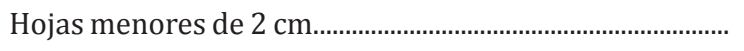 & Nothofagus antarctica \\
\hline $17 \mathrm{~b}$ & 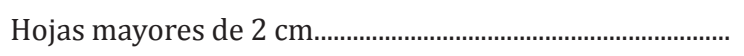 & 18 \\
\hline $18 \mathrm{a}$ & 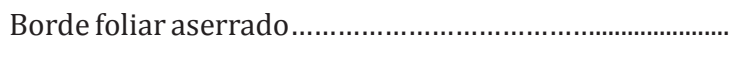 & Populus nigra \\
\hline $18 \mathrm{~b}$ & Borde foliar ondulado, con 2 dientes entre 2 venas........ & Nothofagus pumilio \\
\hline $19 \mathrm{a}$ & 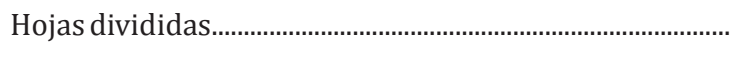 & 20 \\
\hline $19 \mathrm{~b}$ & Hojas simples. & 21 \\
\hline $20 \mathrm{a}$ & Hojas grandes $(>10 \mathrm{~cm})$ como la de los helechos.............. & Lomatia ferruginea \\
\hline $20 \mathrm{~b}$ & 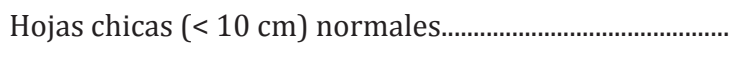 & Weinmannia trichosperma \\
\hline $21 \mathrm{a}$ & 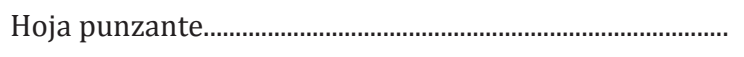 & Podocarpus nubigenus \\
\hline $21 b$ & 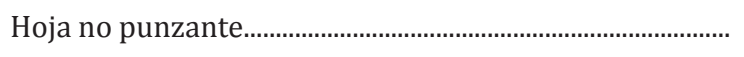 & 22 \\
\hline $22 \mathrm{a}$ & 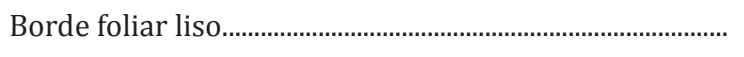 & Drimys winteri \\
\hline $22 b$ & 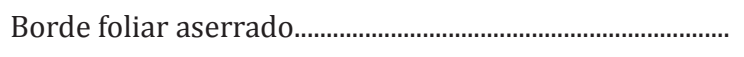 & 23 \\
\hline $23 a$ & 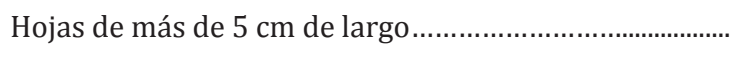 & Caldcluvia paniculada \\
\hline $23 b$ & Hojas de menos de $5 \mathrm{~cm}$ de largo & 24 \\
\hline $24 a$ & Hojas blandas, opacas, mayores de $3 \mathrm{~cm}$ & Maytenus magellanica \\
\hline $24 \mathrm{~b}$ & Hojas duras, brillantes, menores de $3 \mathrm{~cm}$ & 25 \\
\hline $25 a$ & 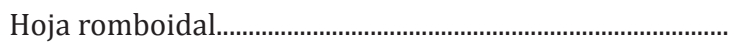 & Nothofagus nitida \\
\hline $25 b$ & Hoja no romboidal...... & 26 \\
\hline $26 a$ & 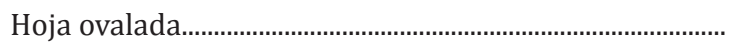 & Nothofagus betuloides \\
\hline $26 b$ & Hoja lanceolada....... & Nothofagus dombeyi \\
\hline $27 \mathrm{a}$ & 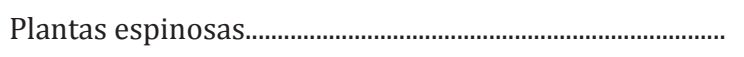 & 28 \\
\hline $27 \mathrm{~b}$ & Plantas inermes, sin espinas...... & 36 \\
\hline $28 \mathrm{a}$ & 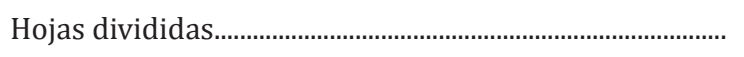 & Rosa rubiginosa \\
\hline $28 \mathrm{~b}$ & Hojas enteras.................. & 29 \\
\hline $29 \mathrm{a}$ & 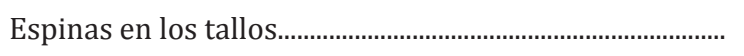 & 30 \\
\hline $29 \mathrm{~b}$ & 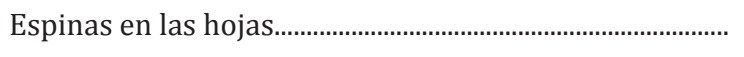 & 32 \\
\hline $30 \mathrm{a}$ & 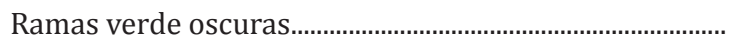 & Colletia hystrix \\
\hline $30 \mathrm{~b}$ & 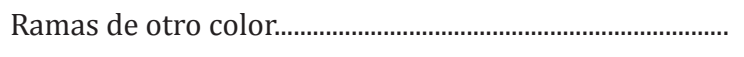 & 31 \\
\hline $31 \mathrm{a}$ & 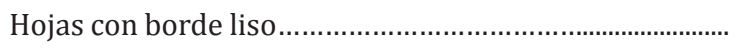 & Berberis microphylla \\
\hline $1 \mathrm{~b}$ & 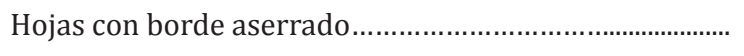 & Discaria chacaye \\
\hline $32 \mathrm{a}$ & 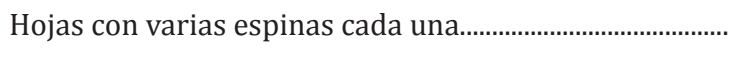 & 33 \\
\hline $2 \mathrm{~b}$ & Hojas con una espina terminal (mucrón)............................. & 35 \\
\hline & Flores con pétalos unidos en un tubo..................................... & Desfontainia fulgens \\
\hline & 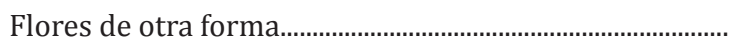 & 34 \\
\hline
\end{tabular}


34a Flores amarillo-anaranjadas

34b Flores rojo-anaranjadas

$35 \mathrm{a}$

$35 \mathrm{~b}$

$36 \mathrm{a}$

$36 \mathrm{~b}$

$37 \mathrm{a}$

$37 \mathrm{~b}$

$38 \mathrm{a}$

$38 \mathrm{~b}$

$39 a$

$39 \mathrm{~b}$

$40 \mathrm{a}$

$40 \mathrm{~b}$

$41 \mathrm{a}$

$41 b$

$42 \mathrm{a}$

$42 \mathrm{~b}$

$43 a$

$43 \mathrm{~b}$

$44 \mathrm{a}$

$44 \mathrm{~b}$

$45 a$

$45 \mathrm{~b}$

$46 a$

$46 \mathrm{~b}$

$47 a$

$47 \mathrm{~b}$

$48 a$

$48 \mathrm{~b}$

$49 a$

$49 \mathrm{~b}$

$50 \mathrm{a}$

$50 \mathrm{~b}$

$51 \mathrm{a}$

$51 b$

$52 \mathrm{a}$

$52 \mathrm{~b}$

$53 a$

$53 \mathrm{~b}$

$54 \mathrm{a}$

$54 \mathrm{~b}$

$55 a$

$55 \mathrm{~b}$

$56 a$

$56 \mathrm{~b}$

Hojas menores de $1 \mathrm{~cm}$.

Hojas mayores de $1 \mathrm{~cm}$.

Sin hojas en invierno..

Con hojas en invierno.

Flores poco aparentes.

Flores solitarias rojizas

Hoja alargada.

Hojas trilobada

Hojas pequeñas, escamosas.

Hojas más grandes

Plantas erguidas arbustivas.

Hojas de a dos por nudo..

Hojas de a 1 por nudo

Borde foliar aserrado

Borde foliar liso.

Tallo como una caña

Tallo de otra forma

Flores vistosas solitarias.

Flores de otro color.

Flores de otra forma

Flores rojas

Flores rosadas.

Flores de color amarillo

Flores de color blanco

Hojas en manojos.

Hojas de hasta 2 por nudo

Hojas de a dos por nudo

Hojas de a una por nudo.

Flor muy corta $(<1 \mathrm{~cm})$

Flor alargada $(>1 \mathrm{~cm})$

Hojas de color verde oscuro.

Hojas de color verde claro.

Hoja más larga que ancha.

Hoja tan larga como ancha
Flores vistosas de color rojo y fucsia.

Flores verde-amarillentas reunidas en amentos

Fruto una baya de color negro

Fruto (semilla) seco rojo-amarillento

Plantas rastreras subarbustivas.

Hojas mayores de $3 \mathrm{~mm}$ de largo.

Hojas menores de $3 \mathrm{~mm}$ de largo.

Flores poco aparentes agrupadas en cabezuelas.

Flores de color rojas o rosadas

Flores como pequeños copihues
Berberis ilicifolia o Berberis serrato-dentata

Berberis darwinii

Gaultheria mucronata

Gaultheria phillyreifolia

37

40

Fuchsia magellanica

38

Myoschilos oblonga

39

Salix fragilis

Ribes magellanicum o Ribes trilobum

41

42

Empetrum rubrum

Lepidothamnus fonkii

43

46

Myrteola nummularia

44

Gaultheria antarctica

45

Maytenus disticha

Lebetanthus myrsinites

Chusquea culeou

47

48

54

49

51

Philesia magellanica

50

Escallonia rubra

Escallonia rosea

Azara lanceolada

52

Escallonia serrata

53

Myrceugenia ovata

\section{4}

Escallonia virgata

Escallonia alpina

56

Chiliotrichum diffusum

Baccharis patagonica o Baccharis obovata

Baccharis magellanica o Baccharis nivalis 


\section{DISCUSIÓN}

La gran diversidad vegetacional y florística de plantas leñosas encontrada en la comuna de Tortel corresponde a la vegetación de un clima templado frío y muy lluvioso con una precipitación que supera los 3000 $\mathrm{mm}$ de precipitación promedio anual (Di Castri y Hajek, 1976) por lo que no existen meses secos durante el año y que según Amigo y Ramírez (1998) corresponde a un bioclima supratemperado y a un ombrotipo ultraperhúmedo propio de las islas de los archipiélagos del oceáno Pacífico al Sur de la isla grande de Chiloé, donde predominan bosques perennifolios de Nothofagus y Turberas pantanosas (Álvarez et al., 2010). Aunque la vegetación estudiada conserva aún muchos rodales en estado prístino sin intervención humana, el Cipresal (Pilgerodendronetum uviferae) está muy intervenido por la explotación del importante recurso maderero del Ciprés de las Guaitecas (Vidal et al., 2011).

Los turbales son pobres en especies leñosas, con excepción de aquellos pulvinados en los cuales existen pequeños árboles, pero aquellos esfagnosos cuentan con importantes recursos para el futuro como lo son el musgo pon-pon (Sphagnum magellanicum) utilizado como material absorbente y acumulador de agua y la turba, que tiene aplicaciones como combustibles que aún permanecen intactos (Zegers et al., 2006). Su explotación planteará seguramente a futuro un serio problema de sustentabilidad pues puede alterarse el ciclo hídrico, si desaparecen esos importantes reservorios acuíferos (Díaz et al., 2008).

La flora leñosa de la Comuna de Tortel tiene una gran riqueza específica, caracterizada por una alta diversidad de formas de crecimiento que ocupan los diferentes hábitats que ofrece la vegetación aún poco intervenida de la comuna. Efectivamente, la poca intervención antrópica se refleja en el hecho de que sólo 3 (4\%) especies leñosas de las 61 encontradas son alóctonas y de ellas solamente la rosa mosqueta (Rosa rubiginosa) puede considerarse un arbusto invasor, pero que no coloniza los bosques primarios, sino praderas antropogénicas abandonadas, es decir, vegetación ruderal o semi-natural, que por lo demás, es escasa en la comuna (Quiroz et al., 2009; Frey y Loesch, 2010).

El canelo (Drimys winteri) es la especie leñosa con presencia en el mayor número de comunidades vegetales distintas, lo que corresponde a su rol ecológico como especie pionera y como base para la recuperación del bosque talado por su alta capacidad de regeneración (Lépez, 1998). Los renovales de canelo en lugares donde creció el bosque de coigüe de Chiloé son importantes en la comuna.

La clave entregada al final de los resultados permite identificar (determinar) las especies leñosas por cualquier lego y además, evita el tener que revisar muchas fotografías para reconocer la especie, como sucede ac- tualmente con muchos manuales de flora. Sin embargo, como todo instrumento tiene sus limitaciones, estas pueden ser más fácilmente sorteadas por un conocedor de la flora local, aun cuando no tenga formación biológica ni botánica.

\section{CONCLUSIONES}

La vegetación de la Comuna de Tortel está integrada por 4 formaciones de bosques, matorrales, estepa y turbales, presentado los primeros 5 comunidades: bosque de coigüe de Chiloé, bosque de coigüe de Magallanes, bosque de coigüe, bosque de ñire y colihue y bosque de ciprés de las Guaitecas. Matorrales sólo aparece uno, el matorral achaparrado de lenga al igual la estepa altoandina que sólo presenta una comunidad de brecillo. Los turbales también presentan una gran diversidad con turberas esfagnosas (con musgo pon-pon como dominante) en tierras bajas y turberas pulvinadas y graminosas en tierras altas. Esta alta diversidad vegetacional entrega abundantes lugares de vida y hábitats para flora y fauna.

La flora leñosa de la Comuna de Tortel presenta 61 especies con variadas formas de vida, árboles, arbustos, subarbustos, lianas, epífitos y parásitos. En esta flora domina el elemento nativo, presentándose sólo 3 especies introducidas: el álamo, la rosa mosqueta y un sauce. Para determinar esta rica flora leñosa se entrega una clave dicotómica que permite su identificación científica. Por último, se presenta una caracterización simplificada de cada especie.

Se espera que con este aporte los habitantes de Tortel y también los turistas puedan conocer esta flora y ayudar a su protección y conservación.

\section{AGRADECIMIENTOS}

Trabajo financiado parcialmente por el Proyecto FIA-PI-C-2044-1 "Evaluación cuantitativa y cualitativa del musgo Sphagnum sp. como forma de conocer su uso, manejo y protección en la Comuna de Tortel, XI Región"

\section{REFERENCIAS}

ÁLVAREZ, M., SAN MARTÍN, C., NOVOA, C., TOLEDO, G., RAMÍREZ, C. 2010. Diversidad florística, vegetacional y de hábitats en el Archipiélago de Los Chonos (Región de Aisén, Chile). Anales Instituto Patagonia (Chile) 38(1): 34-55.

AMIGO, J., RAMÍREZ, C. 1998. A bioclimatic classification of Chile: woodland communities in the temperate zone. Plant Ecology 136: 9-26.

AMIGO, J., RAMÍREZ, C., QUINTANILLA, L. 2004. The Nothofagus nítida (Phil.) Krasser woodlands of southern Chile in the northern half of their range: phytosociological posi- 
tion. Acta Botanica Gallica 151 (1): 3-31.

BRAUN-BLANQUET, J. 1979. Fitosociología, bases para el estudio de las comunidades vegetales. H. Blume Ediciones, Madrid.

CAIN, S.A. 1950. Life-forms and phytoclimate. The Botanical Review 16 (1): 1-32.

DI CASTRI, F., HAJEK, E. 1976. Bioclimatología de Chile. Editorial Universidad Católica de Chile, Santiago.

DÍAZ, M., LARRAÍN, J., ZEGERS, G., TAPIA, C. 2008. Caracterización florística e hidrológica de turberas de la Isla Grande de Chiloé, Chile. Revista Chilena de Historia Natural 81: 455-468.

FREY, W., LOESCH, R. 2010. Geobotanik Pflanze und Vegetation in Raum und Zeit. Spektrum Akademischer Verlag, Heidelberg.

GODOY, R., RAMÍREZ, C., PUENTES, O. 2001. Plantas parásitas vasculares de Chile. En: Baldini, A., Pancel, L. (Eds.), Agentes de daño en el bosque nativo. GTZ/CONAF, Editorial Universitaria, Santiago, pp. 53-88.

KNAPP, R. 1984. Considerations on quantitative parameters and qualitative attibutes in vegetation analysis and in phytosociological relevés. In: Knapp, R. (Ed.), Sampling methods and taxon analysis in vegetation science. Dr. W, Junk Publishers, La Haya, pp. 77-119.

LÉPEZ, P. 1998. Estudio fitosociológico del "Parque Oncol" (Valdivia, Chile). Tesis Ingeniería Forestal, Universidad Austral de Chile. 97 p.

MOORE, D. 1982. Flora of Tierra del Fuego. Anthony Nelson, Shropshire \& Missouri Botanical Garden, Missouri.

MUELLER-DOMBOIS, D., ELLENBERG, H. 1974. Aims and Methods of Vegetation Ecology. John Wiley \& Sons, New York.

MUÑOZ, C. 1959. Sinopsis de la flora chilena. Comisión Central de Publicaciones, Universidad de Chile, Santiago.

OBERFORFER, E. 1960. Pflanzensoziologischen in Chile - Ein Vergleich mit Europa. Flora eta Vegetatio Mundi 2: 1-208.

PISANO, E. 1977. Fitogeografía de fuego-patagonia chilena. I. Comunidades vegetales entre los $52^{\circ}$ y $56^{\circ} \mathrm{S}$. Anales del instituto de la Patagonia 8: 121-250.

QUIROZ, C.L., PAUCHARD, A., MARTICORENA, A., CAVIERES, L.A. 2009. Manual de plantas invasoras del Centro-Sur de Chile. Laboratorio de Invasiones Biológicas, Universidad de Concepción, Concepción.

RAMÍREZ, C. 1968. Die Vegetation der Moore der Cordillera Pelada, Chile. Bericht der Oberhessisch. Ges. für Natur- und Heilkunde zu Giessen NF. Naturwiss. Abt. 36:
95-101.

RAMÍREZ, C., SAN MARTÍN, C., OJEDA, P. 1997. Muestreo y tabulación fitosociológica aplicados al estudio de los bosques nativos. Bosque 18 (2): 19-27.

RAMÍREZ, C., SAN MARTÍN, C., SAN MARTÍN, J. 2004. Colmatación por macrófitos del complejo lacustre Vichuquén (VII Región, Chile) y clave de determinación. Revista Geográfica de Chile Terra Australis 49: 179-196.

RAMÍREZ, C., BARRERA, J., CONTRERAS, D., SAN MARTÍN, J. 1988. Estructura y regeneración del matorral de Ulex europaeus en Valdivia, Chile. Medio Ambiente 9 (1): 143-149.

RAMÍREZ, C., DE LA MAZA, E., MUÑOZ, I., SAN MARTÍN, C. 1994. GENSE: un programa computacional para determinar malezas. Serie Carillanca 43: 31-49.

RAMÍREZ, C., SAN MARTÍN, C., NOVOA, C., VILLAGRA, J., AMIGO, J. 2009. Uso de tablas fitosociológicas para detectar especies vegetales con problemas de conservación. Agro Sur 37(2): 91-102.

RAMÍREZ, C., SANDOVAL, V., SAN MARTÍN, C., ÁLVAREZ, M., PÉREZ, Y., NOVOA, C. 2012. El paisaje rural antropogénico de Aisén, Chile: Estructura y dinámica de la vegetación. Gayana Botánica 69(1): 219-231.

RODRÍGUEZ, R., MARTICORENA, A., TENEB, E. 2008. Plantas vasculares de los ríos Baker y Pascua, Región de Aisén, Chile. Gayana Botánica 65(1): 39-70.

SAN MARTÍN, C., SANDOVAL, V., ÁLVAREZ, M., VIDAL, O., PÉREZ, Y., SOLÍS, J.L. 2014. Comparación de etapas de degradación vegetacional con manejo pecuario utilizando valores bioindicadores de Ellenberg en la Patagonia Chilena. Bosque 35(2): 141-154.

VIDAL, O. 2007. Flora Torres del Paine - Guía de Campo. Editorial Fantástico Sur. Punta Arenas.

VIDAL, O., BANNISTER, J.R., SANDOVAL, V., PÉREZ, Y., RAMÍREZ, C. 2011. Woodland communities in the Chilean cold-temperate zone (Baker and Pascua basins): Floristic composition and morpho-ecological transition. Gayana Botanica 68 (2): 141-154.

WINK, M. 2006. Schriftzeichen im Logbuch des lebens: Molekulare Evolutionsforschung. Biologie in unserer Zeit 36 (1): 26-37.

ZEGERS, G., LARRAÍN, J., DÍAZ, M.F., ARMESTO, J.J. 2006. Impacto ecológico y social de la explotación de pomponales y turberas de Sphagnum en la Isla Grande de Chiloé. Revista Medio Ambiente y Desarrollo (Chile) 22: 28-34.

ZULOAGA, F., MORRONE, O., BELGRANO, M. 2008. Catálogo de las plantas vasculares del cono sur. Missouri Botanical Garden Press, Missouri. 
